\title{
Documento
}

\section{Sistema Nacional de Educação articulado ao Plano Nacional de Educação*}

\author{
Dermeval Saviani \\ Universidade Estadual de Campinas, Faculdade de Educação
}

No texto que encaminhei como subsídio à preparação da Conferência Nacional de Educação (CONAE), procurei reunir elementos teóricos e históricos que pudessem auxiliar na compreensão da temática central referente ao Sistema Nacional de Educação e ao Plano Nacional de Educação (PNE). Apenas ao final apresentei breves indicações sobre o problema prático-político da construção do sistema e da elaboração do plano.

Procurei explicitar a noção de sistema em correlação com o conceito de estrutura, mostrando sua manifestação no campo educativo para caracterizar o significado e as exigências contidas na noção de sistema educacional. Nesse contexto, evidenciei que, assim como de modo geral o sistema é produto da ação sistematizada, isto é, da capacidade humana de agir intencionalmente segundo objetivos previamen-

* Texto base da exposição feita no Simpósio de Abertura da Conferência Nacional de Educação (CONAE), em Brasília, no dia 29 de março de 2010. A Revista Brasileira de Educação agradece aos coordenadores da CONAE a autorização para a publicação do texto neste número.

te formulados, o sistema educacional é resultado da educação sistematizada.

A partir daí abordei o contexto histórico em que se deu a emergência dos sistemas nacionais de ensino, o que ensejou a generalização do uso do termo sistema na educação, emprestando-lhe o caráter de uma espécie de termo primitivo, não carecendo, pois, de definição. Nessa acepção difusa, o termo sistema se revela polissêmico, prenhe de ambiguidades e imprecisões. Em consequência, procurei depurá-lo de suas imprecisões, mostrando que frequentemente o termo se aplica não ao sistema propriamente dito, mas às suas partes constitutivas. Daí expressões como "sistema de ensino fundamental", "sistema de ensino médio", "sistema de ensino profissional", "sistema de educação básica", "sistema de ensino superior", "sistema escolar", "sistema estadual de ensino", "sistema municipal de ensino", "sistema federal de ensino", "sistema de ensino comercial (industrial, agrícola)" etc., como se fossem coisas diferentes quando, na verdade, são apenas partes do mesmo sistema educacional em seu conjunto.

Não bastasse isso, são frequentes também expressões como "sistema público de ensino ou de 
educação", "sistema particular de ensino" e "sistema livre de ensino". Ora, a primeira expressão é pleonástica, porque o sistema só pode ser público, já que uma de suas características é a autonomia, o que implica normas próprias que obrigam a todos os seus integrantes. E, obviamente, somente o Estado, isto é, o poder público tem a prerrogativa de definir normas que obrigam a todos. Disso resulta que a segunda expressão é contraditória, pois os particulares não podem emitir normas que obrigam a todos; logo, não pode haver sistema particular de educação. Finalmente, a terceira expressão não faz sentido, pois o ensino livre é tal exatamente porque não segue as normas do sistema; logo, está fora dele.

Com essa aproximação ao significado do sistema educacional, registrei o papel histórico desempenhado pelo sistema nacional de ensino tendo em vista a universalização do ensino elementar e a consequente erradicação do analfabetismo nos países em que foi de fato implantado. Constatando que o Brasil não se encontra entre esses países, passei então a considerar os obstáculos que historicamente impediram a organização do Sistema Nacional de Educação em nosso país, classificando-os em quatro tipos: a) os obstáculos econômicos decorrentes da histórica resistência à manutenção da educação pública no Brasil; b) os obstáculos políticos caracterizados pela descontinuidade nas políticas educativas; c) os obstáculos filosófico-ideológicos, isto é, a prevalência das ideias ou mentalidades pedagógicas refratárias à organização da educação na forma de um sistema nacional; d) os obstáculos legais materializados na resistência à incorporação da ideia de sistema nacional na nossa legislação educacional, cuja ponta de lança se ancorava na suposta e logicamente inconsistente tese da inconstitucionalidade da proposta de Sistema Nacional de Educação.

Convém acrescentar que a palavra sistema assume também, no uso corrente, a conotação de modo de proceder, de forma de organização, de maneira de arranjar os elementos de um conjunto, o que remete ao aspecto do método. Assim, é comum, sobre qualquer assunto, alguém dizer para outra pessoa: meu sistema é diferente do seu. Por exemplo, uma dona de casa ou uma cozinheira diz para a outra: o sistema que adoto em minha casa, ou meu sistema de cozinhar, é diferente do seu. A questão emblemática desse uso corrente é o verbo italiano sistemare, que significa arrumar, pôr as coisas em ordem, ordenar elementos formando um conjunto. Ora, em educação também é frequente usar o termo sistema para designar determinados procedimentos metodológicos ou didáticos. Daí aparecer, no âmbito da teoria pedagógica, expressões como "Sistema Decroly", "Sistema Montessori", "Sistema (ou Plano) Dalton", "Sistema Winnetka", transladando-se para o plano da forma de funcionamento do ensino em determinadas empresas educacionais que, convertidos em pacotes, são aplicados sistematicamente e vendidos inclusive para redes de escolas públicas sob o nome de sistema. Daí as denominações "Sistema COC", "Sistema Anglo", "Sistema Positivo", "Sistema Objetivo", "Sistema Oficina", "Sistema Etapa", "Sistema Uno de Ensino" etc. Evidentemente, quando estamos considerando a questão do Sistema Nacional de Educação, colocamonos num plano muito mais abrangente do que esses usos da palavra "sistema" sugerem.

Após saudar a retomada do tema no contexto brasileiro atual em que ocorre a Conferência Nacional de Educação, advertindo que ainda persistem dificuldades, concluí o texto apresentando algumas indicações para a construção do Sistema Nacional de Educação em nosso país articulando-o com a questão do Plano Nacional de Educação. São esses dois aspectos que me proponho a aprofundar neste artigo.

\section{Sobre o Sistema Nacional de Educação}

Se o sistema pode ser definido como a unidade de vários elementos intencionalmente reunidos de modo a formar um conjunto coerente e operante, conclui-se que o Sistema Nacional de Educação é a unidade dos vários aspectos ou serviços educacionais mobilizados por determinado país, intencionalmente reunidos de modo a formar um conjunto coerente que opera eficazmente no processo de educação da população do referido país.

Vê-se, então, que se trata de unidade da variedade e não unidade da identidade. Portanto, contrariamen- 
te ao que por vezes se propaga, sistema não é uma unidade monolítica, indiferenciada, mas unidade da diversidade, um todo que articula uma variedade de elementos que, ao se integrarem ao todo, nem por isso perdem a própria identidade; ao contrário, participam do todo, integram o sistema na forma de suas respectivas especificidades. Isso significa que uma unidade monolítica é tão avessa à ideia de sistema quanto uma multiplicidade desarticulada.

Portanto, a construção de um Sistema Nacional de Educação nada tem de incompatível com o regime federativo. Ao contrário, eu diria que a forma própria de responder adequadamente às necessidades educacionais de um país organizado sob o regime federativo é exatamente por meio da organização de um Sistema Nacional de Educação. Com efeito, o que é a federação senão a unidade de vários estados que, preservando suas respectivas identidades, intencionalmente se articulam tendo em vista assegurar interesses e necessidades comuns? E não é exatamente por isso que o nível articulador da federação, a instância que representa e administra o que há de comum entre os vários entes federativos se chama precisamente União? Ora, assim sendo, a federação postula, portanto, o sistema nacional que, no campo da educação, representa a união dos vários serviços educacionais que se desenvolvem no âmbito territorial dos diversos entes que compõem a federação.

Aclarando um pouco mais essa questão, importa distinguir federação de confederação. A confederação é a associação de países soberanos que se articulam em função de determinados pontos de interesse comum em circunstâncias específicas. A federação é a união estável e permanente de estados autônomos, mas não soberanos. ${ }^{1}$ Isso significa que, numa federação, a sobe-

${ }^{1}$ Cabe lembrar que o uso dos termos nem sempre corresponde ao preciso significado dos conceitos. Por exemplo, sabemos que a Suíça é também chamada de Confederação Helvética, como resultado da união dos diferentes cantões que compunham a Helvetia. No entanto, de fato, trata-se de uma federação, pois os cantões não são soberanos, e por isso não têm a prerrogativa de estabelecer relações com os demais países. Tal prerrogativa é delegada rania pertence à União e, por isso, é em seu âmbito que os estados depositam a responsabilidade das relações que se estabelecem com os demais países.

Consequentemente, o argumento que tende a contestar a construção do Sistema Nacional de Educação em nome do princípio federativo está confundindo federação com confederação. ${ }^{2}$ De certa forma, essa confusão é compreensível, uma vez que o movimento federalista, especificamente na Europa, teve como uma de suas vertentes mais fortes a negação do Estado Nacional, como se pode ver na constatação de Lucio Levi registrada no verbete "Federalismo" do Dicionário de Política, organizado por Bobbio, Matteucci e Pasquino:

De fato, do ponto de vista histórico, as determinações positivas da teoria do Federalismo foram se esclarecendo através da experiência da negação da divisão do gênero humano em Estados soberanos. E já que essa divisão se manifestou numa forma mais aguda na Europa das nações, historicamente o Federalismo se tem definido como a negação do Estado nacional. (Levi, apud Bobbio, Matteucci \& Pasquino, 1999, p. 476)

Ora, isso ocorre porque, do ponto de vista federalista, postula-se a transformação das nações europeias de Estados soberanos em unidades autônomas, mas integrantes de uma federação que seria, esta sim, portadora do atributo de soberania. Trata-se, então, de negar os Estados nacionais soberanos, confederados ou não, para afirmar a existência de Estados autônomos federados.

Nesse contexto, é compreensível também o receio de confiar a atribuição educativa por meio do sistema

à União, isto é, ao Estado suíço, como ocorre normalmente nos regimes federativos.

${ }^{2}$ Para uma análise mais acurada da distinção entre federação e confederação, pode-se recorrer aos dicionários de política, dentre os quais se destaca o organizado por Norberto Bobbio, Nicola Matteucci e Gianfranco Pasquino (1999), no qual os verbetes confederação e federação encontram-se, respectivamente, às p. $218-220$ e $475-486$. 
escolar ao governo central, que, controlando também o exército, incidiria na "lógica tendencialmente totalitária do Estado nacional, que emprega seu poder para fazer de seus cidadãos bons soldados" (idem, p. 481).

Diferente é a situação dos Estados Unidos da América, em que os estados autônomos se uniram numa federação, constituindo e afirmando, portanto, um Estado nacional soberano. Nesse caso, assim como ocorre também no Brasil, negar o Estado nacional com base em suas unidades federativas seria negar a própria federação, substituindo-a por uma confederação, que implicaria dotar de soberania os estados antes federados.

Feitas essas considerações, podemos concluir que, dada uma federação como a brasileira, com seu arcabouço jurídico encabeçado não por acaso pela Constituição Federal, a forma plena de organização do campo educacional é traduzida pelo Sistema Nacional de Educação. Sua construção flui dos dispositivos constitucionais regulamentados pela Lei de Diretrizes e Bases da Educação Nacional (LDB), que é prerrogativa exclusiva da União e se especifica na legislação complementar. Constitui-se, desse modo, um sistema de educação pleno, obviamente público, inteiramente autônomo, com normas próprias que obrigam todos os seus integrantes em todo o território nacional. No âmbito dos estados, preserva-se um grau próprio de autonomia que lhes permite baixar normas de funcionamento do ensino, mas sem a plenitude de que goza a União, uma vez que devem subordinar-se às diretrizes e bases traçadas por ela, esfera que escapa à sua atribuição. E se passamos ao nível municipal, a autonomia torna-se bem mais restrita, porque sequer a Constituição lhes faculta estabelecer normas próprias, o que é admitido apenas em caráter complementar pela LDB.

Deve-se frisar, contudo, que a diferença de graus de autonomia não significa redução de importância para as instâncias que detêm menor autonomia. É comum afirmar-se que o município é a instância mais importante, pois é aí que, concretamente, vivem as pessoas. Desse ponto de vista, o estado e a União se configuram como instâncias abstratas, já que sua realidade se materializa, de fato, no recorte dos municípios. Ora, mas se assim é, então está claro que a configuração dos estados e da União, sua estrutura, organização e administração são operadas por indivíduos concretos, cidadãos reais, ou seja, os habitantes dos municípios. Portanto, se a autonomia se concentra mais nos estados do que nos municípios é porque no âmbito do estado ela se exercita em relação a todos os municípios que o integram e não apenas por parte de cada município em confronto com os demais. $\mathrm{O}$ mesmo se diga da União, cuja autonomia se exerce em relação a todas as unidades federativas e não apenas na contraposição entre elas. Em última instância, são os munícipes que atuam simultaneamente nas três instâncias que, obviamente, se fortalecem reciprocamente na medida em que se estreitam os laços de articulação que as unem em torno de propósitos e interesses comuns.

Não cabe, pois, postularem-se autonomias artificiais enunciando discursos que não correspondem à realidade efetiva. No caso da educação, para ficar no nosso campo de interesse, o discurso da autonomia local ou regional com as normas decorrentes teve efeitos bem diferentes do proclamado, o que pode ser constatado tanto no plano diacrônico, isto é, historicamente, como no plano sincrônico, ou seja, nas condições atuais. Assim, por exemplo, a historiografia registra que o Ato Adicional de 1834 teve o propósito de descentralizar a instrução primária conferindo maior grau de autonomia às províncias, o que lhes permitiria maior margem de criatividade e adequação da instrução às suas necessidades e características específicas. Mas não foi propriamente isso o que ocorreu. A tendência que prevaleceu foi que, embora as reformas do governo imperial tivessem validade apenas para o chamado município neutro, isto é, a cidade do Rio de Janeiro, capital do Império, as províncias acabavam por tomá-las como modelo na organização da instrução pública nos respectivos territórios, reproduzindo as mesmas medidas adotadas pelo governo central. E isso vem se repetindo, em maior ou menor grau, até os dias atuais. 
Em contrapartida, é preciso também ter presente que a melhor forma de fortalecer as instâncias locais não é necessariamente conferir-lhes autonomia, deixando-as, de certo modo, à própria sorte. Na verdade, a melhor maneira de respeitar a diversidade dos diferentes locais e regiões é articulá-los no todo, e não isolá-los. Isso porque o isolamento tende a fazer degenerar a diversidade em desigualdade, cristalizando-a pela manutenção das deficiências locais. Inversamente, articuladas no sistema, enseja-se a possibilidade de fazer reverter as deficiências, o que resultará no fortalecimento das diversidades em benefício de todo o sistema. Nesse sentido, apesar das proclamações em contrário, parece indisfarçável a conclusão de que a municipalização do ensino fundamental se configurou como um retrocesso, de modo especial nos estados que, como São Paulo, haviam assumido, com certa consistência, a responsabilidade por esse grau de ensino desde a implantação do ensino primário na forma da disseminação dos grupos escolares. O panorama que hoje se descortina, mesmo com o antídoto representado pelo Fundo de Manutenção e Desenvolvimento do Ensino Fundamental e de Valorização do Magistério (FUNDEF) seguido do Fundo de Manutenção e Desenvolvimento da Educação Básica e de Valorização dos Profissionais da Educação (FUNDEB), é aquele em que municípios pobres tendem a ter um ensino pobre, municípios remediados, um ensino remediado, e municípios ricos, um ensino mais satisfatório. Configura-se, dessa forma, um processo de aprofundamento das desigualdades que apenas recentemente está se procurando reverter com as ações que integram o Plano de Desenvolvimento da Educação (PDE).

Uma compreensão mais precisa do significado e das implicações do regime federativo permitiria assumir com maior radicalidade e coerência essa condição, o que redundaria em importante simplificação do aparato jurídico com economia de esforços e ganho de eficiência e eficácia no funcionamento das instituições. Assim, seria dispensável que cada estado devesse elaborar as respectivas constituições repetindo tudo que lhe compete acatar da Constituição Federal, acrescentando-lhe as normas específicas.
Como membros da Federação, é deles, isto é, dos estados, a Constituição Federal. Pois não é isso o que o próprio nome está dizendo quando a constituição é adjetivada de "federal"? As constituições dos estados poderiam, simplesmente, começar com o seguinte cabeçalho: "Com base no cumprimento integral das normas estabelecidas na Constituição Federal, o estado (do Amazonas) reger-se-á pelas seguintes normas específicas". Algo semelhante ocorreria com as leis orgânicas dos municípios em relação às respectivas constituições estaduais.

De modo similar, também na educação, constituído o sistema nacional, as normas se estendem a todos os estados e municípios, o que os dispensaria de reiterar as normas comuns, bastando estabelecer as normas tendentes a ajustar aquelas regras comuns às particularidades de cada estado ou município.

Em suma, deve-se fixar claramente as seguintes posições:

a) Trata-se de construir um verdadeiro Sistema Nacional de Educação, isto é, um conjunto unificado que articula todos os aspectos da educação no país inteiro, com normas comuns válidas para todo o território nacional e com procedimentos também comuns visando assegurar educação com o mesmo padrão de qualidade a toda a população do país. Não se trata, portanto, de entender o Sistema Nacional de Educação como um grande guarda-chuva com a mera função de abrigar 27 sistemas estaduais de ensino, incluído o do Distrito Federal, o próprio sistema federal de ensino e, no limite, 5.565 sistemas municipais de ensino, supostamente autônomos entre si. Se for aprovada uma proposta nesses termos, o Sistema Nacional de Educação se reduzirá a uma mera formalidade, mantendo-se, no fundamental, o quadro de hoje, com todas as contradições, os desencontros, as imprecisões e as improvisações que marcam a situação atual, de fato avessa às exigências da organização da educação na forma de um sistema nacional.

Penso que o risco apontado se faz presente na proposta contida no documento base desta CONAE quando enuncia a construção de um sistema nacional articulado de educação, em relação ao qual observei tratar-se de um pleonasmo, pois sistema já implica, 
no próprio conceito, a ideia de articulação, sendo inconcebível um sistema não articulado. A isso me foi respondido que, não obstante a evidência lógica de meu argumento, fazia-se necessário frisar o caráter articulado, tendo em vista a realidade do regime federativo vigente em nosso país. Impunha-se, assim, a exigência de articular, no sistema nacional, os vários sistemas estaduais e municipais de ensino. Acendeuse, então, a luz amarela de advertência: é aí que mora o perigo. De fato, minha implicância com o adjetivo "articulado" poderia ser facilmente afastada se o que estivesse em questão fosse tão somente um problema de linguagem, pois, nesse contexto, poderíamos simplesmente admitir que se trata de um reforçativo, uma ênfase discursiva que, em lugar de prejudicar, ajudaria a fixar mais firmemente o significado do conceito de sistema e o modo de o concretizar praticamente.

Diferentemente de uma mera questão de linguagem, no entanto, o risco do enunciado referente ao sistema nacional articulado reside na sua eventual redução a uma função de simples articulador dos sistemas estaduais e municipais de ensino. Não. Isso não basta. É preciso ir além. É preciso instituir um sistema nacional em sentido próprio, que, portanto, não dependa das adesões autônomas e a posteriori de estados e municípios. Sua adesão ao sistema nacional deve decorrer da participação efetiva na sua construção submetendo-se, em consequência, às suas regras. Não se trata, pois, de conferir a estados e municípios, com base nos respectivos sistemas autônomos, a prerrogativa de aderir ou não a este ou àquele aspecto que caracteriza o sistema nacional.

Eis por que me parece possível prever que, se sair desta Conferência um projeto de lei instituindo o Sistema Nacional de Educação como instância articuladora dos sistemas estaduais e municipais de ensino; se esse projeto for para o Congresso, que, num arroubo de entusiasmo ou indiferença o aprove integralmente, nós teremos apenas mais um rótulo a frequentar o discurso educacional. E será mantida a situação atual, em que o Ministério da Educação (MEC) demonstra certo empenho em formular políticas e implementar ações no âmbito da educação básica, ficando, porém, na dependência da adesão dos governos de estados e prefeituras sujeitos às oscilações determinadas pelas disputas partidárias e pessoais em torno do exercício do poder nessas instâncias federativas.

b) Como já foi explicitado, o sistema só pode ser público. Portanto, não há que transigir com os supostos direitos de educar dos particulares; trate-se das famílias, de associações, congregações, empresas ou outros tipos de entidades, enaltecendo-se a importância de sua contribuição. As instituições privadas, em suas diferentes modalidades, integrarão o sistema precisamente como particulares, e é nessa condição que darão sua contribuição específica para o desenvolvimento da educação brasileira. Deve-se entender que, quanto mais autenticamente particulares elas forem, melhor se tipifica sua contribuição própria. Portanto, não cabe travesti-las de públicas, seja pela transferência de recursos na forma de subsídios e isenções, seja pela transferência de poder, admitindo-as na gestão e operação do complexo das instituições públicas que integram o sistema.

Não se pode, também, enfraquecer o caráter público do Sistema Nacional de Educação a pretexto de que a educação é uma tarefa não apenas do governo, mas de toda a sociedade. De fato, não é uma tarefa de governo, mas de Estado. E é uma tarefa de toda a sociedade, na medida em que o Estado, enquanto guardião do bem público, expressa, ou deveria expressar, os interesses de toda a sociedade. Nessa condição, toda a sociedade deveria não apenas se sentir representada no Estado, mas vivenciar o Estado como coisa sua. Nesses termos, a forma pela qual a sociedade, em seu conjunto, estará cuidando da educação é reforçando seu caráter público e cobrando do Estado a efetiva priorização da educação. Deve-se, portanto, fazer reverter a tendência hoje em curso, de diluir as responsabilidades educativas do poder público transferindo-as para iniciativas de filantropia e de voluntariado. Com efeito, tal tendência configura um retrocesso diante das conquistas do Estado moderno. É como se estivéssemos retornando ao início da era moderna, quando a questão da instrução popular era tratada como um problema de caridade pública. Essa fase foi ultrapassada e a ela não devemos jamais retornar, sob pena de anularmos 
todo o desenvolvimento da sociedade moderna, que desembocou na tese da escola pública universal, gratuita, laica e obrigatória, concebida como direito de todos e dever do Estado.

c) A instância normativa e deliberativa do sistema será exercida por um órgão determinado, que corresponde, hoje, ao Conselho Nacional de Educação (CNE). Em analogia com o campo político, essa instância exerce as funções correspondentes ao legislativo e judiciário, pois além de baixar as normas de funcionamento do sistema, julga as eventuais pendências e decide, em última instância, sobre os recursos das instâncias inferiores. Assim sendo, trata-se de um órgão de Estado e não de governo. Deve, pois, como ocorre com os poderes legislativo e judiciário, gozar de autonomia financeira e administrativa, não podendo ficar, como hoje ocorre, na dependência total do Executivo. Suas deliberações, em consequência, devem entrar em vigor independentemente da homologação do Ministério da Educação. Para tanto, sua composição não deve ocorrer por representações das entidades sociais que de alguma forma se ligam à educação, o que acabaria por lhe conferir um caráter corporativo. Isso quer dizer que o critério de indicação dos membros do CNE deve ter por base as qualificações decorrentes da experiência no campo à luz da folha de serviços prestados à educação, independentemente de seu vínculo maior ou menor com este ou aquele tipo de instituição, assim como neste ou naquele nível ou modalidade de educação.

Posso ilustrar esse ponto com meu próprio caso. Em meados da década de 1980 fui indicado para o Conselho Estadual de Educação de São Paulo. Na época, eu era professor em tempo integral na PUC de São Paulo e colaborava parcialmente na UNICAMP. Fui indicado em razão de minha participação no movimento dos educadores, e não como representante da PUC ou da UNICAMP. E, no Conselho, eu não atuava como representante de minha instituição, defendendo os projetos e propostas de seu interesse. $\mathrm{O}$ que estava em causa era o melhor desenvolvimento da educação no estado de São Paulo, mesmo que determinadas medidas tomadas nessa direção viessem topicamente contrariar interesses e expectativas da própria instituição em que eu trabalhava.

d) Na construção do Sistema Nacional de Educação deve-se implantar uma arquitetura com base no ponto de referência do regime de colaboração entre a União, os estados, o Distrito Federal e os municípios, conforme disposto na Constituição Federal, efetuando repartição das responsabilidades entre os entes federativos, todos voltados para o mesmo objetivo de prover educação com o mesmo padrão de qualidade a toda a população.

$\mathrm{Na}$ repartição das responsabilidades, os entes federativos concorrerão na medida de suas peculiaridades e de suas competências específicas consolidadas pela tradição e confirmadas pelo arcabouço jurídico. Assim, as normas básicas que regularão o funcionamento do sistema serão de responsabilidade da União, consubstanciadas na Lei de Diretrizes e Bases da Educação Nacional e no Plano Nacional de Educação, traduzidas e especificadas pelas medidas estabelecidas no âmbito do Conselho Nacional de Educação. Os estados e o Distrito Federal poderão expedir legislação complementar, adequando as normas gerais a eventuais particularidades locais.

O financiamento do sistema será compartilhado pelas três instâncias, conforme o regime dos fundos de desenvolvimento educacional. Assim, além do FUNDEB, que deverá ser aperfeiçoado, cabe criar também um Fundo de Manutenção da Educação Superior (FUNDES). Se no caso do FUNDEB a maior parte dos recursos provém de estados e municípios, cabendo à União papel complementar, em relação ao FUNDES, a responsabilidade da União será dominante, entrando os estados apenas em caráter complementar, limitando-se aos casos de experiência já consolidada na manutenção de universidades.

A formação de professores, a definição da carreira e as condições de exercício docente constituem algo que dificilmente pode ser confiado aos municípios. Com efeito, a própria LDB, pelo inciso $\mathrm{V}$ do artigo 11, impede-os de atuar na formação de professores, uma vez que poderão se dedicar a outros níveis de ensino ulteriores ao fundamental "somente quando estiverem 
atendidas plenamente as necessidades de sua área de competência e com recursos acima dos percentuais mínimos vinculados pela Constituição Federal à manutenção e desenvolvimento do ensino". Dado que a formação de professores ocorre, como regra, no nível superior e, transitoriamente, no nível médio, escapa aos municípios essa atribuição. Segue-se que as questões relativas ao magistério constituem matéria de responsabilidade compartilhada entre União e estados.

A responsabilidade principal dos municípios incidirá sobre a construção e conservação dos prédios escolares e de seus equipamentos, assim como sobre a inspeção de suas condições de funcionamento, além, é claro, dos serviços de apoio, como merenda escolar, transporte escolar etc. Efetivamente são esses os aspectos em que os municípios têm experiência consolidada. Os municípios, de modo geral, estão equipados para regular, por legislação própria, a ocupação e o uso do solo. Rotineiramente cabe às prefeituras examinar projetos relacionados aos mais variados tipos de construção, verificando sua adequação à finalidade da obra a ser construída. Assim, quer se trate de moradias, de hospitais, de restaurantes de igrejas etc., o órgão municipal verificará se o projeto atende às características próprias do tipo de construção preconizado à luz da finalidade que lhe caberá cumprir. Ora, é evidente que, em se tratando das escolas, as prefeituras também podem cumprir, sem qualquer dificuldade, essa função. Obviamente isso não impede que os municípios assumam, em caráter complementar e nos limites de suas possibilidades, responsabilidades específicas no campo educacional, mesmo no âmbito daquelas funções que cabem prioritariamente aos estados e à União.

Em suma, o Sistema Nacional de Educação integra e articula todos os níveis e modalidades de educação com todos os recursos e serviços que lhes correspondem, organizados e geridos, em regime de colaboração, por todos os entes federativos sob coordenação da União. Fica claro, pois, que a repartição das atribuições não implica exclusão da participação dos entes aos quais não cabe a responsabilidade direta pelo cumprimento daquela função. Eles participarão por meio dos respectivos colegiados, acompanhando e apresentando subsídios que venham a tornar mais qualificadas as decisões tomadas. E assumirão responsabilidades diretas nos aspectos que lhes correspondem por meio das secretarias e conselhos estaduais de educação e das secretarias e conselhos municipais de educação sempre que tal procedimento venha a concorrer para a flexibilização e maior eficácia da operação do Sistema Nacional de Educação, sem prejuízo, evidentemente, do comum padrão de qualidade que caracteriza o sistema.

e) Por fim, e com certeza o mais importante, deve-se considerar com toda a atenção e cuidado o problema do conteúdo da educação a ser desenvolvido no âmbito de todo o Sistema. Conforme os documentos legais, a começar pela Constituição Federal e a LDB, a educação tem por finalidade o pleno desenvolvimento da pessoa, o preparo para o exercício da cidadania e a qualificação para o trabalho. Levando-se em conta que esses objetivos se referem indistintamente a todos os membros da sociedade brasileira considerados individualmente, podemos interpretar, com Gramsci (1975, vol. III, p. 1547), que o objetivo da educação é conduzir cada indivíduo até a condição de ser capaz de dirigir e controlar quem dirige.

Fica claro que tal objetivo não poderá ser atingido com currículos que pretendam conferir competências para a realização das tarefas de certo modo mecânicas e corriqueiras demandadas pela estrutura ocupacional, concentrando-se, e ainda de forma limitada, na questão da qualificação profissional e secundarizando o pleno desenvolvimento da pessoa e o preparo para o exercício da cidadania.

Diferentemente dessa tendência dominante, a organização curricular dos vários níveis e modalidades de ensino no âmbito do Sistema Nacional de Educação deverá tomar como referência a forma de organização da sociedade atual, assegurando sua plena compreensão por parte de todos os educandos. Isso significa que se deve promover a abertura da caixa-preta da chamada "sociedade do conhecimento". A educação a ser ministrada deverá garantir a todos o acesso aos fundamentos e pressupostos que tornaram possível a 
revolução microeletrônica que está na base dos processos de automação que operam no processo produtivo e das tecnologias da informação que se movem nos ambientes virtuais da comunicação eletrônica.

Assim, além de tornar acessíveis os computadores pela disseminação dos aparelhos e em vez de lançar a educação na esfera dos cursos a distância de forma açodada, é preciso garantir não apenas o domínio técnicooperativo dessas tecnologias, mas a compreensão dos princípios científicos e dos processos que as tornaram possíveis. Se continuarmos pelos caminhos que estamos trilhando, não parece exagerado considerar que estamos de fato realizando aquelas profecias dos textos de ficção científica que previram uma humanidade submetida ao jugo de suas próprias criaturas, sendo dirigidas por máquinas engrenadas em processos automáticos, pois não deixa de ser verdade que cada vez mais nos relacionamos com as máquinas eletrônicas, especificamente com os computadores, considerando-os fetichisticamente pessoas a cujos desígnios nós nos sujeitamos e, sem conseguirmos compreendê-los, atribuímos a eles determinadas características psicológicas traduzidas em expressões que os técnicos utilizam para nos explicar seu comportamento, tais como: "ele, o computador, não reagiu bem ao seu procedimento"; "ele é assim mesmo, às vezes aceita o que você propõe e às vezes não aceita" etc.

Nas condições atuais, não é mais suficiente alertar contra os perigos da racionalidade técnica advogando-se uma formação centrada numa cultura de base humanística voltada para filosofia, literatura, artes e ciências humanas à revelia do desenvolvimento das chamadas "ciências duras". É preciso operar um giro da formação na direção de uma cultura de base científica que articule, de forma unificada, num complexo compreensivo, as ciências humano-naturais que estão modificando profundamente as formas de vida, passando-as pelo crivo da reflexão filosófica e da expressão artística e literária. É este o desafio que o Sistema Nacional de Educação terá de enfrentar. Somente assim será possível, além de qualificar para o trabalho, promover o pleno desenvolvimento da pessoa e o preparo para o exercício da cidadania.

\section{Sobre o Plano Nacional de Educação}

Foi acertado o encaminhamento da organização da Conferência Nacional de Educação ao articular, no tema central, a questão da construção do Sistema Nacional de Educação com o Plano Nacional de Educação. Há, efetivamente, íntima relação entre esses dois conceitos. Como se mostrou, o sistema resulta da atividade sistematizada; e a ação sistematizada é aquela que busca intencionalmente realizar determinadas finalidades. É, pois, uma ação planejada. Sistema de ensino significa, assim, uma ordenação articulada dos vários elementos necessários à consecução dos objetivos educacionais preconizados para a população à qual se destina. Supõe, portanto, planejamento. Ora, se "sistema é a unidade de vários elementos intencionalmente reunidos, de modo a formar um conjunto coerente e operante" (Saviani, 2008, p. 80), as exigências de intencionalidade e coerência implicam que o sistema se organize e opere segundo um plano. Consequentemente, há estreita relação entre sistema de educação e plano de educação.

Podemos dizer que a formulação do Plano Nacional de Educação se põe como uma exigência para que o Sistema Nacional de Educação mantenha permanentemente suas características próprias. Com efeito, é preciso atuar de modo sistematizado no sistema educacional; caso contrário, ele tenderá a distanciar-se dos objetivos humanos, caracterizandose especificamente como estrutura (resultado coletivo inintencional de práxis intencionais individuais). Esse risco é particularmente evidente no fenômeno que vem sendo chamado de "burocratismo". Este consiste em que, a um novo processo, apliquem-se mecanicamente formas extraídas de um processo anterior. Assim sendo, o funcionamento do sistema acaba caindo numa rotina em que as ações se tornam mecânicas, automáticas, rompendo o movimento dialético ação-reflexão-ação, que é condição sine qua non da educação sistematizada e, portanto, da prática educativa própria do sistema educacional. Isso porque o modo de existência do homem é tal que uma práxis que se estrutura em função de determinado(s) 
objetivo(s) não se encerra com a sua realização, mas traz a exigência da realização de novos objetivos, projetando-se numa nova práxis (que só é nova pelo que acrescenta à anterior e porque a pressupõe; na realidade prolonga-a, num processo único que se insere na totalidade do existir).

Portanto, para que o sistema permaneça vivo e não degenere em simples estrutura, burocratizandose, é necessário manter continuamente, em termos coletivos, a intencionalidade das ações. Isso significa que em nenhum momento se deve perder de vista o caráter racional das atividades desenvolvidas. E o plano educacional é exatamente o instrumento que visa introduzir racionalidade na prática educativa como condição para superar o espontaneísmo e as improvisações, que são o oposto da educação sistematizada e de sua organização na forma de sistema.

Mas se o plano educacional é instrumento de introdução da racionalidade na educação, é preciso ter presente que há diferentes tipos de racionalidade.

Historicamente, no Brasil, podemos identificar a origem da ideia de plano na educação a partir da década de 1930. Sua primeira manifestação explícita nos é dada pelo Manifesto dos Pioneiros da Educação Nova, lançado em 1932.

O Manifesto, após diagnosticar o estado da educação pública no Brasil, afirmando que "todos os nossos esforços, sem unidade de plano e sem espírito de continuidade, não lograram ainda criar um sistema de organização escolar à altura das necessidades modernas e das necessidades do país" (Manifesto, 1984, p. 407), enuncia as diretrizes fundamentais e culmina com a formulação de um "plano de reconstrução educacional".

O conceito de plano, no âmbito do Manifesto, assume o sentido de instrumento de introdução da racionalidade científica no campo da educação em consonância com o ideário escolanovista, para o qual “os trabalhos científicos no ramo da educação já nos faziam sentir, em toda a sua força reconstrutora, o axioma de que se pode ser tão científico no estudo e na resolução dos problemas educativos como nos da engenharia e das finanças" (idem, p. 409).
Esse entendimento influenciou, por certo, a Constituição Brasileira de 1934, cujo artigo 150, alínea $a$, estabelecia como competência da União "fixar o plano nacional de educação, compreensivo do ensino de todos os graus e ramos, comuns e especializados; e coordenar e fiscalizar a sua execução, em todo o território do país".

A mesma Constituição de 1934 previu ainda, no artigo 152, um Conselho Nacional de Educação, cuja principal função seria elaborar o Plano Nacional de Educação.

Enquanto para os educadores alinhados com o movimento renovador o plano de educação era entendido como um instrumento de introdução da racionalidade científica na política educacional, para Getúlio Vargas e Gustavo Capanema o plano se convertia em instrumento destinado a revestir de racionalidade o controle político-ideológico exercido pela política educacional.

Durante o período do Estado Novo (1937-1945), Capanema se aproxima da ideia de plano de educação como operacionalização da política educacional, ao entender que "a promulgação de uma lei geral de ensino, ou seja, de um Código da Educação Nacional, apresentava-se como condição prévia para a elaboração de um plano de educação" (Horta, 1997, p. 149-150) que, por sua vez, se constituiria na "base e roteiro das providências de governo" no âmbito educacional.

No período compreendido entre 1946 e 1964 observa-se uma tensão entre duas visões de plano de educação que, de certo modo, expressa a contradição entre as forças que se aglutinaram sob a bandeira do nacionalismo desenvolvimentista que atribuíam ao Estado a tarefa de planejar o desenvolvimento do país, libertando-o da dependência externa, e aquelas que defendiam a iniciativa privada, contrapondo-se à ingerência do Estado na economia e àquilo que taxavam de monopólio estatal do ensino. Ambas as tendências repercutiram no debate que se travou por ocasião da discussão, no Congresso Nacional, do projeto da nossa primeira Lei de Diretrizes e Bases da Educação Nacional. 
A primeira tendência teve como porta-voz Santiago Dantas, que, intervindo no debate na Câmara dos Deputados na sessão de 4/6/1959, salientou a necessidade de o projeto de LDB criar as condições para a construção de um sistema de ensino voltado para a realidade e as necessidades do desenvolvimento brasileiro, criticando o projeto de LDB por ser apenas uma consolidação das leis do ensino. Para ele, a Lei de Diretrizes e Bases não pode ser apenas uma moldura jurídica, mas deve fixar os objetivos, os meios e as condições de planejamento por meio dos quais o Poder Público possa coordenar os esforços da nação no campo educativo (Dantas, 1959, p. 2664). Em seu entendimento, o Plano Nacional de Educação resulta, portanto, mais importante do que a própria Lei de Diretrizes e Bases.

Entretanto, na discussão da LDB prevaleceu a segunda tendência, que defendia a liberdade de ensino e o direito da família de escolher o tipo de educação que deseja para seus filhos, considerando que a ação planificada do Estado trazia embutido o risco de totalitarismo. Em decorrência dessa orientação, a ideia de plano de educação na nossa primeira LDB ficou reduzida a instrumento de distribuição de recursos para os diferentes níveis de ensino. De fato, pretendia-se que o plano garantisse o acesso das escolas particulares, em especial as católicas, aos recursos públicos destinados à educação.

Assim, a Lei de Diretrizes e Bases da Educação Nacional promulgada em 20/12/1961 se refere a "plano de educação" no $\S 2^{\circ}$ do artigo 92. Após estabelecer que "com nove décimos dos recursos federais destinados à educação serão constituídos, em parcelas iguais, o Fundo Nacional do Ensino Primário, o Fundo Nacional do Ensino Médio e o Fundo Nacional do Ensino Superior" ( $\left(1^{\circ}\right)$, o $\S 2^{\circ}$ determina que "o Conselho Federal de Educação elaborará, para execução em prazo determinado, o plano de educação referente a cada fundo". Atendendo àquelas normas legais, o Conselho Federal de Educação elaborou em 1962 um documento (Brasil, 1962) em que procurou, numa primeira parte, traçar as metas para um plano nacional de educação e, numa segunda parte, estabelecer as normas para a aplicação dos recursos correspondentes aos Fundos do Ensino Primário, do Ensino Médio e do Ensino Superior (cf. Horta, 1982, p. 93-125).

Designado para relatar o Plano Nacional de Educação no Conselho Federal de Educação, Anísio Teixeira esclareceu o sentido do preceito legal e arquitetou um procedimento engenhoso para a distribuição dos recursos, detalhando-o no que se refere ao plano do Fundo Nacional do Ensino Primário. Foi esse procedimento que inspirou a criação, em 1996, do Fundo de Manutenção e Desenvolvimento do Ensino Fundamental e de Valorização do Magistério (FUNDEF), orientação que foi mantida com sua substituição pelo Fundo de Manutenção e Desenvolvimento da Educação Básica e de Valorização dos Profissionais da Educação (FUNDEB) em dezembro de 2006.

A partir de 1964, o protagonismo no âmbito do planejamento educacional se transferiu dos educadores para os tecnocratas, o que, em termos organizacionais se expressou na subordinação do Ministério da Educação ao Ministério do Planejamento, cujos corpos dirigente e técnico eram, via de regra, oriundos da área de formação correspondente às ciências econômicas.

Essa tendência se explicita na reforma do ensino traduzida pela lei n. 5.692/1971, cujo artigo 53 define que "o Governo Federal estabelecerá e executará planos nacionais de educação, esclarecendo no parágrafo único que o planejamento setorial da educação deverá atender às diretrizes e normas do Plano-Geral do Governo, de modo que a programação a cargo dos órgãos da direção superior do Ministério da Educação e Cultura se integre harmonicamente nesse Plano-Geral" (Saviani, 1996, p. 136). Nesse contexto, os planos para a área de educação decorriam diretamente dos Planos Nacionais de Desenvolvimento (PNDs), recebendo, por isso mesmo, a denominação de Planos Setoriais de Educação e Cultura (PSECs).

Com o advento da "Nova República" passou-se "de uma estratégia de formulação de políticas, planejamento e gestão tecnocrática, concentrada no topo da pirâmide no governo autoritário, para o polo oposto, da fragmentação e do descontrole, justificado pela des- 
centralização, mas imposto e mantido por mecanismos autoritários" (Kuenzer, 1990, p. 61).

Quanto ao PNE atualmente em vigor, ele resultou de duas propostas: uma elaborada pelo MEC na gestão Paulo Renato, do governo FHC, e outra gestada no II Congresso Nacional de Educação. A proposta do MEC, dado o empenho em reorganizar a educação na égide da redução de custos traduzida na busca da eficiência sem novos investimentos, revelou-se um instrumento de introdução da racionalidade financeira na educação. Pelo empenho em se guiar pelo princípio da "qualidade social", poderíamos considerar que a segunda proposta entende o plano como um instrumento de introdução da racionalidade social na educação.

Em suma: na década de 1930 o conceito de plano assumiu o sentido de introdução da racionalidade científica na educação; no Estado Novo, metamorfoseou-se em instrumento destinado a revestir de racionalidade o controle político-ideológico exercido pela política educacional; com a LDB de 1961, converteu-se em instrumento de viabilização da racionalidade distributiva dos recursos educacionais; no regime militar, caracterizou-se como instrumento de introdução da racionalidade tecnocrática na educação; na "Nova República", sua marca foi o democratismo com o que a ideia de introduzir, pelo plano, uma espécie de racionalidade democrática se revestiu de ambiguidade; finalmente, na era FHC, o plano se transmutou em instrumento de introdução da racionalidade financeira na educação.

Considerando que o prazo de vigência do atual PNE se esgota em 9/1/2011, será necessário elaborar uma nova proposta e encaminhar ao Congresso Nacional o projeto do novo Plano Nacional de Educação. É preciso proceder a uma revisão detida e cuidadosa do atual PNE, refazendo o diagnóstico das necessidades educacionais a serem atendidas pelo sistema educacional. E esse trabalho deverá evidentemente ser realizado já em perfeita sintonia com os encaminhamentos relativos à construção do Sistema Nacional de Educação.

Nesse trabalho convém tirar proveito das lições decorrentes da elaboração do plano atual. Cabe, a meu ver, repensar a estrutura do plano concentrando-se nos aspectos fundamentais e, em consequência, enxugando o texto e reduzindo o número de metas, seja pela aglutinação daquelas afins, seja fixando-se nos aspectos mais significativos. Isso se faz necessário para viabilizar o acompanhamento e o controle, tendo em vista, por um lado, avaliar o grau em que o plano está sendo posto em prática e, por outro, cobrar dos responsáveis o efetivo cumprimento das metas. Com efeito, há de se convir que é muito difícil para a população ter presente um conjunto de 295 metas para acompanhar de perto e vigiar para que sejam efetivadas.

Ao efetuar o diagnóstico e traçar as metas, será necessário tomar como referência os níveis e modalidades de ensino. Uma estratégia a ser adotada pode ser definir as metas gerais, deixando o detalhamento para ser efetuado no âmbito das instâncias do Sistema Nacional de Educação responsáveis pela execução delas. À guisa de ilustração, tomemos o seguinte exemplo: considerando que todas as questões de infraestrutura ligadas às condições de funcionamento e manutenção dos prédios escolares ficarão a cargo dos municípios, definida a meta, digamos, de adequação, em cinco anos, de todas as escolas aos padrões estabelecidos, cada município deverá detalhar, à luz de sua situação específica, os procedimentos que conduzirão ao cumprimento da meta no prazo estipulado.

Uma atenção especial deverá ser dada no PNE à questão do financiamento, não porque seja garantia da realização das metas, mas porque é condição indispensável, ainda que não suficiente, do seu cumprimento. Nesse aspecto, como já reiterei em várias oportunidades, cabe considerar, à luz do que se proclama como sendo próprio da "sociedade do conhecimento", a educação como eixo do próprio projeto de desenvolvimento do país. Assim sendo, serão destinados recursos de grande monta para equipar plenamente o Sistema Nacional de Educação. Por esse caminho será possível duplicar imediatamente o percentual do Produto Interno Bruto (PIB) investido em educação, saltando, já em 2011, no início da vigência do novo PNE, dos atuais $4,7 \%$ para $9,4 \%$. Teríamos aí um patamar para tratar, de fato, a educação com o grau de prioridade 
que é proclamado nos discursos. E isso é plenamente viável, porque os recursos investidos na educação não serão subtraídos da economia, mas, ao contrário, serão seu elemento propulsor, dinamizando seus diversos setores - agricultura, indústria, comércio e serviços. Educação é, pois, um bem de produção, e não apenas um bem de consumo.

Em síntese, aquilo que se impõe é a mudança do modelo de desenvolvimento econômico. Até agora o modelo vem tendo por eixo o automóvel, o que se evidencia no fordismo, depois substituído pelo toyotismo, com todos os efeitos colaterais negativos daí decorrentes: verticalização das cidades, congestionamento do tráfego, poluição ambiental, aquecimento global, além do seu caráter concentrador da renda, com o aprofundamento das desigualdades sociais. A mudança desse eixo para a educação permitirá um desenvolvimento com maior distribuição da renda e estimulador da igualdade social e, além de não apresentar efeitos colaterais negativos, já traz consigo o antídoto aos efeitos negativos, como se constata na educação ambiental, educação para o trânsito etc.

Complementarmente à questão da revisão da estrutura do plano, é necessário atentar para os mecanismos a serem previstos tendo em vista a garantia de que o plano seja de fato colocado em prática. A lei n. 10.172, que instituiu o atual PNE, previu no art. $3^{\circ}$ avaliações periódicas da implementação do plano, estabelecendo, no $\S 1^{\circ}$, o acompanhamento de sua execução pelo Poder Legislativo e determinando, no $\S 2^{\circ}$, que a primeira avaliação seria feita no quarto ano de vigência do plano. No entanto, nada disso foi feito. É importante que agora, na formulação do novo PNE, essas questões sejam devidamente equacionadas. Uma maneira de assegurar institucionalmente esse processo de acompanhamento e avaliação da execução do plano será restabelecer, no âmbito do Sistema Nacional de Educação, a proposta de criação do Fórum Nacional de Educação como órgão representativo da sociedade civil do campo educacional; ele deverá se reunir periodicamente - digamos, a cada dois ou três anos -, tendo como tarefa precípua o referido acompanhamento.

\section{Conclusão}

A primeira oportunidade de organizarmos um Sistema Nacional de Educação no Brasil ocorreu na década de 1930, com o Manifesto dos Pioneiros da Educação Nova e com a Constituição Federal de 1934, que inscreveu a exigência de fixação, pela União, das diretrizes da educação nacional e a formulação do Plano Nacional de Educação. Essa oportunidade foi perdida com o advento do Estado Novo.

Uma nova oportunidade se abriu em decorrência da Constituição Federal de 1946, que reiterou a exigência de fixação, por parte da União, das diretrizes e bases da educação nacional. Já no projeto original, a questão da organização do Sistema Nacional de Educação não foi assegurada à vista da assimilação, feita pelos próprios renovadores, do sistema nacional à tese da centralização do ensino. Por isso a centralidade foi posta nos sistemas estaduais, admitindo-se o sistema federal em caráter supletivo. Na sequência, os interesses das escolas particulares, capitaneados pela Igreja Católica, guiando-se pelo temor do suposto monopólio estatal do ensino, concorreram para afastar a preocupação com o Sistema Nacional de Educação.

Finalmente, a terceira oportunidade nos foi dada pela elaboração da nova Lei de Diretrizes e Bases da Educação Nacional, em decorrência da atual Constituição Federal, promulgada em 5/10/1988. Dessa vez, a organização do Sistema Nacional de Educação foi inviabilizada pela interferência governamental, que preferiu uma LDB minimalista para não comprometer sua política educacional, que promovia a desresponsabilização da União pela manutenção da educação, ao mesmo tempo que concentrava em suas mãos o controle por meio de um sistema nacional de avaliação do ensino em todos os seus níveis e modalidades.

Após três oportunidades perdidas, esperamos que não seja desperdiçada esta possibilidade que se abre agora, com a realização desta Conferência Nacional de Educação. Espero que as considerações que acabei de apresentar contribuam para a realização dessa expectativa, que, tenho certeza, é compartilhada pela grande maioria dos educadores de nosso país. 


\section{Referências bibliográficas}

BOBBIO, Norberto; MATTEUCCI, Nicola; PASQUINO, Gianfranco. Dicionário de política, 2 vols., 12. ed. Brasília: Editora UnB, 1999.

BRASIL. MEC. CFE. Plano Nacional de Educação, 1962. Revista Brasileira de Estudos Pedagógicos, v. XXXVIII, n. 88, p. 108-126, out./dez. 1962.

DANTAS, Santiago. Discurso na Câmara dos Deputados. Diário do Congresso Nacional, S.I., de 5 de junho de 1959. Rio de Janeiro, 1959. p. 2664.

GRAMSCI, Antonio. Quaderni del carcere (edizione critica dell'Istituto Gramsci a cura de Valentino Gerratana). 4 vols. Torino: Einaudi, 1975.

HORTA, José Silvério Baía. Liberalismo, tecnocracia e planejamento educacional no Brasil. São Paulo: Cortez/Autores Associados, 1982.

Plano Nacional de Educação: da tecnocracia à participação democrática. In: CURY, Carlos Roberto Jamil; HORTA, José Silvério Baía; BRITO, Vera Lúcia Alves. Medo à Liberdade e compromisso democrático: LDB e Plano Nacional de Educação. São Paulo: Editora do Brasil, 1997. p. 137-206.

KUENZER, Acácia. Política educacional e planejamento no Brasil: os descaminhos da transição. In: CALAZANS, Maria Julieta et al. Planejamento e educação no Brasil. São Paulo: Cortez, 1990. p. 55-88.
MANIFESTO dos Pioneiros da Educação Nova (1932). Revista Brasileira de Estudos Pedagógicos, v. 65, n. 150, p. 407-425, maio/ago. 1984.

SAVIANI, Dermeval. Educação brasileira: estrutura e sistema. 10. ed. Campinas: Autores Associados, 2008. . Política e educação no Brasil. 3. ed. Campinas: Autores Associados, 1996.

DERMEVAL SAVIANI é professor emérito da UNICAMP e coordenador geral do Grupo Nacional de Estudos e Pesquisas História, Sociedade e Educação no Brasil (HISTEDBR), atuando nas áreas de teorias da educação, história da educação, política educacional e formação docente. Publicações recentes: Escola e democracia (Campinas: Autores Associados, 2008. Ed. especial comemorativa dos 25 anos de lançamento e da $40^{\mathrm{a}}$ ed.); História das ideias pedagógicas no Brasil (Campinas: Autores Associados, 2007); A pedagogia no Brasil: história e teoria (Campinas: Autores Associados, 2008); PDE - Plano de Desenvolvimento da Educação: análise crítica da política do MEC (Campinas: Autores Associados, 2009). E-mail: dermevalsaviani@yahoo.com.br

Recebido em março de 2010

Aprovado em março de 2010 
Key words: teaching competences; scale of perception of teaching competences; competitiveness of the private university.

Factores que influencian en la percepción de las competencias para el ejercicio de la docencia

Este artículo analiza las competencias solicitadas para la docencia académica en relación a las características demográficas y funcionales de docentes universitarios. Partiendo de las respuestas de 282 docentes al cuestionario aplicado en una muestra de conveniencia, se realizó un análisis de confiabilidad y validad de constructor, generando una escala para evaluar la percepción de las referidas competencias. A través de técnicas multivariadas, dos grupos de docentes fueron identificados: profesor experimentado $y$ profesor iniciante. $E l$ primero, formado por profesionales con edad más elevada y más tiempo de docencia y permanencia en la institución, valoriza sobremanera las competencias relativas a la habilidad interpersonal, a la capacidad didáctica pedagógica y su abertura a la innovación, cuando comparado al segundo grupo. Los Profesores Iniciantes, con menor tiempo de vinculación a la universidad y poco tiempo en el ejercicio de la docencia, tienen el enfoque direccionado para la obtención de títulos; demostrando no entender lo que las universidades esperan de ellos y, sobretodo, cuales competencias son necesarias desenvolver para conquistar el nivel de los profesores experimentados.

Palabras claves: competencia de los docentes; escala de percepción de competencia de los docentes; competitividad de la universidad privada.
Dermeval Saviani

\section{Sistema Nacional de Educação articulado ao Plano Nacional de Educação}

Versando sobre o tema central da Conferência Nacional de Educação (CONAE), realizada em Brasília de 28 de março a $1^{\circ}$ de abril de 2010 , o texto trata do conceito de Sistema Nacional de Educação em articulação com o Plano Nacional de Educação. Para tanto, após indicar os usos básicos do conceito de sistema, aborda a questão do Sistema Nacional de Educação explorando, em especial, o problema federativo para mostrar a plena compatibilidade da organização do Sistema Nacional de Educação com o regime federativo. Na sequência, aborda o significado histórico do Plano Nacional de Educação mostrando que o plano é uma exigência do sistema, uma vez que a educação sistematizada implica a ação planejada. Assim sendo, o Plano Nacional de Educação constitui o meio pelo qual se pode aferir o grau em que o Sistema Nacional de Educação está cumprindo as metas e objetivos que lhe cabe atingir.

Palavras-chave: Sistema Nacional de Educação; plano nacional de educação; educação brasileira; política educacional

National System of Education articulated with the National Plan of Education

This text which discusses the central theme of the National Conference on Education (CONAE), held in Brasilia from $28^{\text {th }}$ March to $1^{\text {st }}$ April 2010, deals with the concept of a National System of Education in articulation with the National Plan of Education. To that end, after pointing to the basic uses of the concept of system, it discusses the question of the National System of Education exploring the federative question in order to reveal the complete compatibility of the organization of the National System of Education with the federative regime. Thereafter, it deals with the historical meaning of the National Plan of Education demonstrating that the plan is a demand of the system, since planned action is implicit in systematized education. Thus the National Plan of Education is fulfilling those goals and objectives for which it is responsible.

Key words: national system of education, national plan of education, Brazilian education, educational policy

\section{Sistema Nacional de Educación articulado al Plano Nacional de Educación}

Versando sobre el tema central de la Conferencia Nacional de Educación (CONAE), realizada en Brasilia del 28 de marzo al $1^{\circ}$ de abril de 2010, el texto trata del concepto del Sistema Nacional de Educación en articulación con el Plano Nacional de Educación. Por tanto, después de indicar los usos básicos del concepto del sistema, aborda la cuestión del Sistema Nacional de Educación explorando, en especial, el problema federativo para mostrar la plena compatibilidad de la organización del Sistema Nacional de Educación con el régimen federativo. En la secuencia, aborda el significado histórico del Plano Nacional de Educación mostrando que el plano es una exigencia del sistema, una vez que la educación sistematizada envuelve la acción planeada. Así pues, el Plano Nacional de Educación constituye el medio por el cual se puede comparar el grado en que el Sistema Nacional de Educación está cumpliendo las metas y objetivos que le corresponde alcanzar.

Palabras clave: sistema nacional de educación; plano nacional de educación; educación brasileña; política de la educación 